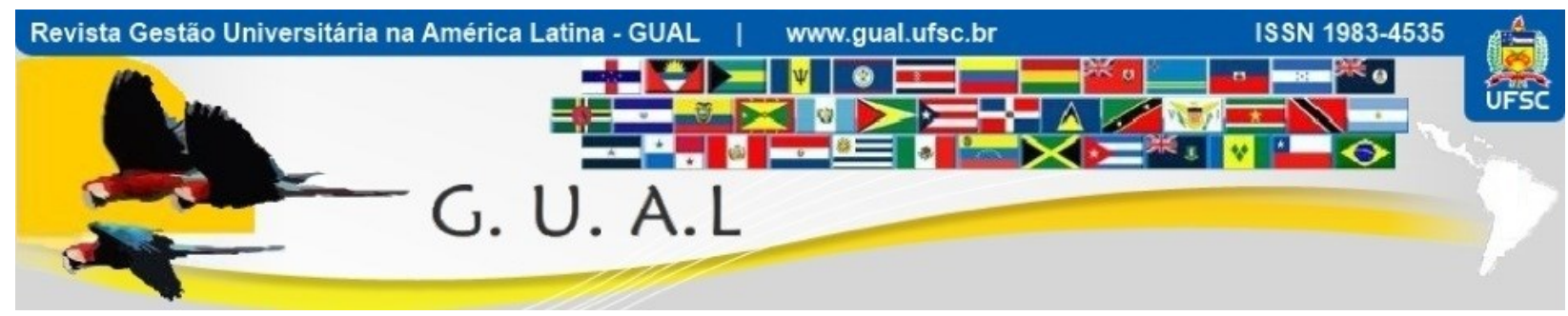

DOI: http://dx.doi.org/10.5007/1983-4535.2017v10n4p22

\title{
DEMONSTRAÇÃO DE VALOR ADICIONADO NA INSTITUIÇÃO DE EDUCAÇÃO SUPERIOR: EVIDÊNCIAS DO MERCADO DE CAPITAIS BRASILEIRO
}

\author{
CREATION AND DISTRIBUTION OF WEALTH IN HIGHER EDUCATION \\ INSTITUTIONS: EVIDENCE FROM THE BRAZILIAN CAPITAL MARKET
}

\author{
Annor da Silva Junior, Doutor \\ Universidade Federal do Espírito Santo - UFES \\ annorsi@gmail.com \\ Vitor Correa da Silva, Doutorando \\ Universidade Federal do Espírito Santo - UFES \\ vitor_correa@msn.com \\ Mariana Ramos de Melo, Mestranda \\ Universidade Federal do Espírito Santo - UFES \\ mariramos.melo@gmail.com \\ Priscilla de Oliveira Martins da Silva, Doutora \\ Universidade Federal do Espírito Santo - UFES \\ priscillamartinssilva@gmail.com
}

Recebido em 25/novembro/2016

Aprovado em 16/outubro/2017

Sistema de Avaliação: Double Blind Review

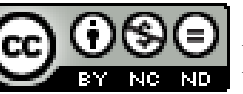

Esta obra está sob uma Licença Creative Commons Atribuição-Uso. 


\title{
RESUMO
}

Verificou-se neste estudo como ocorre a geração e a distribuição de riquezas em Instituições de Educação Superior (IES) brasileiras que se configuram como companhias abertas listadas na Bolsa Valores, Mercadorias e Futuros de São Paulo (BM\&FBovespa). Articulou-se teoricamente o corpo de conhecimento acerca da responsabilidade social corporativa (RSC), do balanço social e da demonstração de valor adicionado (DVA). A DVA é uma demonstração contábil que evidencia a geração e a distribuição de riquezas de companhias. Metodologicamente, realizou-se um estudo de natureza quantitativa e descritiva. Os dados foram coletados por meio da ferramenta Comdinheiro junto a cinco companhias no período de 2010 a 2015. Os dados foram analisados por meio de estatística descritiva dos indicadores de geração e de distribuição de riquezas. Os resultados indicam uma geração de aproximadamente 27,8 bilhões de reais em riqueza no período. O quadro de funcionários foi o agente que recebeu a maior parcela de riqueza, indicando coerência em relação à atividade dessas companhias, qual seja, a educação superior. Como reflexão torna-se necessário repensar a RSC, principalmente em termos da comparação entre a atuação e a transparência de companhias abertas e instituições sem finalidade lucrativa na educação superior brasileira.

Palavras chave: Responsabilidade Social Corporativa. Demonstração de Valor Adicionado. Instituição de Educação Superior. Mercado de Capitais Brasileiro. Companhias Abertas.

\begin{abstract}
This study analyzes how the creation and distribution of wealth occurs in Brazilian Higher Education Institutions (HEINS) which are organized as corporations listed in Brazilian Securities, Commodities, and Futures Exchange (Bolsa de Valores, Mercadorias e Futuros de São Paulo - BM\&FBovespa). It theoretically articulates the body of knowledge about corporate social responsibility (CSR), social balance, and the Value Added Statement (VAS). VAS is a bookkeeping statement that shows data on companies' creation and distribution of wealth. As to methodology, this study is of a quantitative, descriptive nature. Data from five companies, in the period between 2010 and 2015, were collected through a tool called "Comdinheiro". Then, they were analyzed through descriptive statistics of the indicators of creation and distribution of wealth. Results indicate the creation of roughly 27.8 billion reals (Brazilian currency) in wealth throughout the period. Personnel was the agent that received the largest portion in the distribution of the wealth created, which suggests consistency with regard to those companies' activity - higher education. Results imply the necessity of comparatively reconsidering the socially responsible operation of for-profit organizations and nonprofit institutions, especially as to their social role, transparency and accountability to Brazilian society.
\end{abstract}

Keywords: Corporate Social Responsibility. Social Balance. Value Added Statement. Higher Education Institution. Brazilian Capital Market. Corporations. 


\section{INTRODUÇÃO}

Apresenta-se neste artigo os resultados de uma parte de um projeto de pesquisa mais amplo que se propõe a investigar indicadores de mensuração e de evidenciação das práticas de responsabilidade social corporativa (RSC) e de sustentabilidade aplicados às Instituições de Educação Superior (IES) no Brasil. Dedicou-se neste estudo à investigação da geração e da distribuição de riquezas de companhias brasileiras listadas na Bolsa Valores, Mercadorias e Futuros de São Paulo (BM\&FBovespa) que pertencem ao setor da educação superior.

Para conduzir esta pesquisa, articulou-se o corpo de conhecimento relativo à RSC, ao balanço social e à Demonstração de Valor Adicionado (DVA) tendo como locus de investigação o mercado de capitais brasileiro, mais especificamente as companhias brasileiras listadas na BM\&FBovespa. Em relação ao mercado de capitais brasileiro, este estudo dedicase prioritariamente em explorar o setor da educação superior.

A discussão acerca das questões que envolvem a RSC e o universo corporativo tem estado presente na agenda de diversos atores sociais do meio acadêmico e empresarial. Esse interesse está relacionado, entre outros fatores, (1) à necessidade que a sociedade contemporânea tem em discutir sobre o papel social das organizações; (2) à falta de habilidade (e/ou de interesse) do Estado em resolver questões de ordem social; e (3) a crescente tomada de consciência acerca do comportamento empresarial injusto ou discriminatório (XAVIER; MARANHÃO, 2010; FARIA; SAUERBRONN, 2008).

No âmbito dessas discussões observa-se a presença de pontos de vistas contraditórios, sobre o papel social das organizações e as obrigações do Estado. De um lado, Friedman (2014) é de opinião que a única responsabilidade social da organização consiste em utilizar seus recursos para maximizar o lucro em benefício dos acionistas. $\mathrm{O}$ autor vai mais além e questiona a capacidade (e/ou responsabilidade) dos homens de negócios em definir o que é de interesse social e se é tolerável que funções públicas sejam exercidas por gestores de organizações privadas. Nesse sentido, o papel das corporações seria, entre outros, de propiciar circulação de riquezas, produção de bens e serviços, geração de emprego e pagamento de tributos ao Estado (LEAL JUNIOR, 2011), e do Estado seria o de fazer valer, simultaneamente à função arrecadatória e social dos tributos para promover a justiça e o bemestar social, atendendo, com isso, os anseios da sociedade (CARDOSO, 2011; RIBEIRO; GESTEIRO, 2006). 


\section{DEMONSTRAÇÃO DE VALOR ADICIONADO NA INSTITUIÇÃO DE EDUCAÇÃO SUPERIOR: \\ EVIDÊNCIAS DO MERCADO DE CAPITAIS BRASILEIRO \\ DOI: http://dx.doi.org/10.5007/1983-4535.2017v10n4p22}

Porém, de outro lado, há quem considere que o Estado na sociedade contemporânea (decorrente do capitalismo global) vem se caracterizando como um Estado minimalista, com autonomia cada vez mais restrita em decorrência de privatizações e de desregulação de mercados (DUPAS, 2005), tornando-se com isso, ineficiente no cumprimento de sua função social. Considerando a ineficiência do Estado, há seguidores da abordagem da teoria dos stakeholders, como por exemplo Parmar et al. (2010), que defendem a relevância de a gestão corporativa assumir compromissos e considerar os interesses de todas as partes interessadas, mesmo sob a possibilidade de minimizar o retorno para os acionistas. Nesse sentido, como apontam Baret (2006) e Gond e Mullenbach-Servayre (2004), a organização tem as suas responsabilidades aumentadas em que a governança socialmente responsável estaria vocacionada para levar em consideração as necessidades e interesses dos stakeholders.

Além dos compromissos e responsabilidades assumidas com a sociedade, torna-se relevante que as organizações encontrem meios de divulgação de suas práticas e ações de RSC, bem como de mensurar os seus impactos para a sociedade. No contexto da evidenciação das informações de RSC, o balanço social se apresenta como um mecanismo de disclosure social voluntário fundamental para que as organizações apresentem aos seus stakeholders os seus investimentos em RSC (NOVELINI; FREGONESI, 2013; MILANI FILHO, 2008).

Iudícibus et al. (2003) destacam que o balanço social possui quatro vertentes: balanço ambiental; balanço de recursos humanos; Demonstração de Valor Adicionado (DVA); e Benefícios e Contribuições às Sociedade em Geral. Dos componentes do balanço social apontados por Iudícibus et al. (2003), o foco deste estudo volta-se para a DVA.

A DVA é uma demonstração contábil que tem por finalidade evidenciar a geração e a distribuição de riquezas de uma companhia. Em outros termos, a DVA evidencia a parcela do valor adicionado (riqueza gerada) destinada aos detentores de capital, a outros financiadores das atividades da companhia, aos funcionários, à sociedade e o quanto é retido pela companhia (MACHADO; MACEDO; MACHADO, 2015; HALLER; STATEN, 2014).

Esta demonstração contábil tornou-se obrigatória no contexto brasileiro em decorrência do processo de convergência da contabilidade brasileira aos padrões internacionais de contabilidade. Com a promulgação da Lei $n^{0} 11.638 / 2007$ que modificou a Lei $\mathrm{n}^{\mathrm{o}}$ 6.404/1976 (ambas, Leis das Sociedades Anônimas) e da aprovação do Pronunciamento Técnico CPC-09 (CPC, 2008) ficou definida a obrigatoriedade da DVA para 
as Sociedades Anônimas (capital aberto e fechado), bem como os critérios para a sua elaboração.

A adoção das normas internacionais de contabilidade no contexto brasileiro ocorreu em dois momentos distintos: o primeiro que compreendeu os anos de 2008 e 2009 em que a adoção foi facultativa e, o segundo, a partir do ano de 2010, em que a adoção se tornou obrigatória para as companhias presentes no mercado de capitais brasileiro, mais especificamente aquelas com ações negociadas na BM\&FBovespa (GATSIOS et al., 2015). Segundo o site da BM\&FBovespa, 495 companhias encontram-se listadas atualmente na bolsa (BM\&FBOVESPA, 2016), sendo este o tamanho do mercado de capitais brasileiro em que todas as companhias têm a obrigatoriedade de divulgar a DVA.

No período que compreende os anos de 2010 a 2015, em que a divulgação da DVA era obrigatória, observa-se que do total de companhias listadas na BM\&FBovespa, cinco faziam parte do setor educacional superior, quais sejam: a Anhanguera Educacional S.A. (adquirida pela Kroton em 2013), a Estácio Participações S.A. (recentemente adquirida pela Kroton), a GAEC Educação S.A. (ANIMA), a Kroton Educacional S.A. e a Ser Educacional S.A. O setor educacional superior na BM\&FBovespa é relativamente recente, pequeno e todas as companhias fazem parte do segmento denominado de "Novo Mercado", que é o segmento com maiores exigências em termos de regras rígidas de governança corporativa.

Embora pouco representativo em termos do quantitativo de companhias no mercado de capitais brasileiro, os números da educação superior no Brasil e destas companhias são relevantes. Por exemplo, segundo o Censo da Educação Superior de 2013, existiam no Brasil 2.391 IES, ofertando 32.049 cursos superiores, com um total de 7.305.977 alunos matriculados (INEP, 2015). Já em relação às quatro companhias listadas na BM\&FBovespa em 2016, observa-se em seus resultados financeiros relativos ao primeiro trimestre uma receita bruta aproximada de $\mathrm{R} \$ 3,4$ bilhões, apresentando um aumento médio de 6,05\% em relação do primeiro trimestre de 2015. Além disso, observa-se no primeiro trimestre de 2016 que essas IES totalizavam aproximadamente 1.850 .000 alunos matriculados, o que representa aproximadamente $25,32 \%$ do total de matrículas na educação superior brasileira (ESTACIO, 2016; GAEC EDUCAÇÃO, 2016; KROTON, 2016; SER EDUCACIONAL, 2016).

As considerações teóricas e evidências empíricas apresentadas até aqui nortearam a elaboração do problema de pesquisa: Como se caracteriza a geração e a distribuição de riquezas das companhias brasileira do setor educacional da BM\&FBovespa? Definiu-se 
como objetivo geral da pesquisa identificar e analisar como ocorre a geração e a distribuição de riquezas das companhias brasileira do setor educacional da BM\&FBovespa.

Para conduzir a pesquisa, realizou-se um estudo de natureza quantitativa e descritiva (TRIPODI et al., 1981). Os dados foram coletados por meio de triangulação (DENZIN, 1989; JICK, 1979) ao combinar dados relativos à DVA disponível na ferramenta Comdinheiro com dados disponíveis nos sítios eletrônicos das cinco companhias investigadas, bem como no sitio da BM\&FBovepa. Definiu-se como período de investigação os anos de 2010 a 2015 pelo fato deste período a divulgação da DVA ser obrigatória para todas as companhias listadas na BM\&FBovespa. Os dados foram analisados por meio de estatística descritiva dos indicadores de geração e de distribuição de riquezas.

A discussão sobre a RSC, o balanço social e mais especificamente à DVA no contexto da educação superior tem despertado o interesse de pesquisadores e acadêmicos. Por exemplo, Oliveira et al. (2015) investigaram, por meio de uma pesquisa qualitativa, se as ações de responsabilidade social em projetos sociais de uma fundação educacional estão vinculadas ao marketing social. Concluíram que os projetos sociais vinculados ao marketing social fomentam a inclusão social e a promoção do bem comum na luta pelos direitos humanos. Já Nogueira, Garcia e Ramos (2012) realizaram um estudo qualitativo para investigar, junto a uma IES pública, em que aspectos a gestão aproxima-se dos elementos da governança corporativa e suas relações com a responsabilidade social da instituição. Os autores identificaram que, muito embora a instituição não tivesse uma política institucional formalizada de responsabilidade social, havia uma percepção dos respondentes de que a IES caminhava neste sentido. Lohn (2011), por sua vez desenvolveu uma proposta de indicadores de responsabilidade social para as IES.

Por fim, Mazzioni et al. (2014) analisaram a DVA de fundações educacionais de Santa Catarina no período de 2008 a 2011. Os autores concluíram que o valor adicionado é canalizado majoritariamente para a remuneração de pessoal e que as entidades pesquisadas possuem capacidade de geração de riquezas para permitir a continuidade de suas atividades.

A análise dos estudos anteriores apresentados no texto indica, pelo menos em parte, os argumentos centrais que justificam a realização do estudo. Primeiro, que os estudos anteriores priorizaram a investigação de IES e/ou fundações educacionais para investigar os temas RSC, balanço social e DVA por meio da utilização do recorte de pesquisa qualitativo. Segundo que foi negligenciado a atuação de IES pertencentes ao mercado de capitais. Essas instituições, 
por exigências do próprio mercado de capitais, têm como prática a evidenciação de suas informações financeiras, de RSC e de sustentabilidade, apresentando com isso demonstrações contábeis mais confiáveis e, após o ano de 2010, no padrão internacional de contabilidade. Com isso, acredita-se que a investigação do setor de educação superior da BM\&FBovespa, por meio de um recorte quantitativo, poderá gerar uma contribuição relevante para a compreensão de como ocorre a geração e distribuição de riquezas dessas companhias.

Estruturou-se o texto em cinco seções além da introdução. Na próxima seção apresenta-se o referencial teórico do estudo. Na terceira seção descreve-se os aspectos metodológicos da pesquisa. Na quarta e quinta seções apresenta-se respectivamente a apresentação e a discussão dos resultados. Por fim na sexta e última seção indica-se as conclusões da pesquisa.

\section{REFERENCIAL TEÓRICO}

Aborda-se no referencial teórico aspectos conceituais relativos à RSC, ao balanço social, à DVA, à educação superior e ao mercado de capitais. Destaca-se que não há a pretensão de esgotar assuntos tão complexos e extensos, pelo contrário, pretende-se aqui apontar os fundamentos teóricos que nortearam os procedimentos de coleta e de análise dos dados.

\subsection{RESPONSABILIDADE SOCIAL CORPORATIVA E BALANÇO SOCIAL}

No entendimento de Kemper et al. (2013), apesar da RSC ter se tornado uma estratégia central para que organizações avancem em uma trajetória sustentável, o papel e a contribuição da RSC no desempenho da organização ainda permanecem obscuros. Mesmo assim, Jha e Cox (2015) e Callan e Thomas (2009) apontam que tem se observado nas últimas décadas um aumento em investimentos em RSC por parte das organizações. Por exemplo, em 2014, as companhias americanas e inglesas presentes no "Fortune Global 500" investiram 15,2 bilhões de dólares em RSC e em relatório de 2010 publicado pela "The Form for Sustainable and Responsible Investment" que trata da evolução dos investimentos em RSC indica de 3,07 trilhões de dólares dos ativos gerenciados profissionalmente nos Estados Unidos da América foram destinados a investimentos socialmente responsáveis.

No entendimento de Jha e Cox (2015), há duas possibilidades de visões capazes de explicar todo esse interesse e investimentos em RSC por parte das companhias dos Estados 
Unidos da América e da Inglaterra (Reino Unido). A primeira é a visão de maximização dos stakeholders. Considerada por Jah e Cox (2015) como estratégica, esta visão sugere que os investimentos em RSC estão ligados aos interesses dos gestores das companhias em manterem melhores relações com outros stakeholders, como por exemplo, força de trabalho (empregados ou pessoal), fornecedores e clientes que poderão, em contrapartida a essa boa relação, recompensar a companhia (DENG; KANG; LOW, 2013). A segunda visão, chamada por Jah e Cox (2015) de visão de custos dos acionistas, aborda o motivo oculto por trás da RSC. Esta visão sugere que os gestores se engajam em atividades socialmente responsáveis as custas dos recursos investidos pelos acionistas, provavelmente motivado por interesses e benefícios próprios (CRONQVIST et al., 2009; SURROCA; TRIBÓ, 2008).

Considerando as características do mercado de capitais brasileiro de ser (1) identificado como pequeno e subdesenvolvido (BORTOLON; SILVA JUNIOR, 2015; SARLO NETO et al. 2005; NÓBREGA et al., 2000); (2) constituído predominantemente por companhias cuja propriedade é concentrada (LEAL; BORTOLON 2009; SARLO NETO et al. 2005); (3) pela presença de relações familiares no conselho de administração (KPMG 2016); assume-se neste artigo que a visão de RSC mais tipicamente presente nas companhias brasileira é a visão de maximização dos stakeholders (JAH; COX, 2015) principalmente pelo fato da concentração da propriedade indicar a sobreposição entre a estrutura de propriedade e a de gestão. Em outros termos, essa sobreposição indica alinhamento de interesses entre o acionista e o gestor, fazendo com que o gestor não tivesse espaço para expropriar o acionista.

Assumindo a visão de maximização dos stakeholders (JAH; COX, 2015), as companhias brasileiras utilizam a ferramenta do balanço social como forma de comunicação e de divulgação de suas ações sociais aos stakeholders. $O$ balanço social consiste num instrumento contábil que fornece informações de natureza social que revelam a responsabilidade da companhia perante a sociedade (MAZZIONI; TINOCO; OLIVEIRA, 2007).

O balanço social configura-se como um instrumento de divulgação voluntária sob a forma de relatório (ou demonstração) que apresenta as características da organização, o seu relacionamento com seus stakeholders e reflete seus resultados sob os aspectos econômico, social e ambiental (NOVELINI; FREGONESI, 2013; MILANI FILHO, 2008; SANTOS; HASHIMOTO, 2003). Em outros termos, o balanço social tem por finalidade tornar pública a RSC de uma organização (PINTO; RIBEIRO, 2004). 


\section{DEMONSTRAÇÃO DE VALOR ADICIONADO NA INSTITUIÇÃO DE EDUCAÇÃO SUPERIOR: \\ EVIDÊNCIAS DO MERCADO DE CAPITAIS BRASILEIRO \\ DOI: http://dx.doi.org/10.5007/1983-4535.2017v10n4p22}

Na visão e Reis e Medeiros (2007), o balanço social é um instrumento que reúne um conjunto de informações sobre as ações de natureza social e não obrigatórias realizadas por uma companhia com o propósito de gerar um maior bem-estar junto aos seus stakeholders e à sociedade como um todo. Esse instrumento, como apontam Santos (2007) e Iudicibus et al. (2003), estrutura-se por meio de pelo menos quatro vertentes, sendo uma delas a DVA. Porém, mesmo fazendo parte do balanço social, a DVA diferencia-se do primeiro pelo fato daquele ser um relatório não obrigatório e não padronizado (MILANI FILHO, 2008) e este segundo ser uma demonstração contábil obrigatória para as sociedades anônimas e possuir uma forma padronizada de apresentação (MACHADO, 2010; CPC, 2008).

\subsection{DEMONSTRAÇÃO DE VALOR ADICIONADO (DVA)}

Segundo Machado (2010) a DVA possui maior notoriedade em relação às demais vertentes do balanço social, por diversas razões, podendo-se destacar, (1) a existência de um modelo padronizado de apresentação que permite a comparabilidade das informações; (2) a obrigatoriedade de sua publicação para as sociedades anônimas; e, (3) a utilização de dados e informações contábeis para a sua elaboração, proporcionando maior credibilidade, principalmente quando essas demonstrações contábeis são auditadas. A DVA, como aponta Santos (2007, p. 37), “deve ser entendida como a forma mais competente criada pela contabilidade para auxiliar na medição e demonstração da capacidade de geração, bem como de distribuição da riqueza de uma entidade".

Conforme apontam Machado, Macedo e Machado (2015), os dados para a elaboração da DVA são extraídos da contabilidade, sobretudo da Demonstração de Resultado do Exercício (DRE). Porém, essas duas demonstrações contábeis possuem características distintas, enquanto a DRE enfatiza o lucro líquido por meio da utilização do critério da natureza das contas (receitas e despesas), a DVA volta-se para a geração e distribuição de riquezas mediante o critério do benefício da renda da companhia.

Haller e Staten (2014) destacam que o cálculo da DVA é realizado considerando dois caminhos, ou seja, a DVA incorpora dois aspectos distintos que podem ser descritos como a dualidade da medida do valor adicionado, quais sejam: (1) o foco no aspecto econômico e de performance da companhia; e (2) o foco no aspecto social da sociedade. O primeiro aspecto é expresso pelo método indireto (método subtrativo) que revela a criação de valor por meio das atividades da companhia, ou seja, o quanto de valor a companhia agrega aos insumos que 
pode ser obtido pela diferença entre as vendas ou produção e o total de insumos adquiridos de terceiros. Já o segundo aspecto é expresso pelo método direto (método aditivo) que consiste na soma de fatores de produção "trabalho" e "capital", bem como da comunidade representada pelo poder público, ou seja, esse segundo aspecto se concentra na distribuição de riquezas geradas na economia, mostrando que a medida macroeconômica da DVA coloca a atividade econômica da companhia dentro do seu contexto social.

No Brasil, a elaboração da DVA segue as orientações emitidas pelo CPC-09 (CPC, 2008). Segundo essas orientações a DVA deve ser constituída de duas partes. A primeira, apresenta de forma detalhada a riqueza criada pela companhia e contempla a seguinte equação: Receita - Insumos Adquiridos de Terceiros - Depreciação, Amortização e Exaustão + Valor Adicionado Recebido em Transferência. Já a segunda parte, apresenta de forma detalhada como a riqueza gerada pela companhia é distribuída entre os agentes que contribuíram para a sua geração, dentre eles: (a) funcionários (ou pessoal): por meio dos salários, benefícios e FGTS; (b) governo: por meio de tributos federais, estaduais e municipais, que representam a remuneração pela estrutura social, política e econômica que propiciam as condições fundamentais para a operação da companhia; (c) financiadores: remuneração de capitais de terceiros, por meio de juros, aluguéis, direitos autorais entre outros; e (d) detentores do capital: remuneração do capital próprio, por meio de juros sobre o capital próprio, dividendos, lucros retidos ou prejuízos do exercício (MACHADO; MACEDO; MACHADO, 2015; CPC, 2008). É com base nestas orientações que serão analisadas as DVA das companhias brasileiras do setor da educação superior presentes na BM\&FBovespa.

\subsection{O SETOR DE EDUCAÇÃO SUPERIOR E O MERCADO DE CAPITAIS BRASILEIRO}

Historicamente, a educação superior no Brasil sempre foi fortemente regulamentada. Essa regulamentação determinou que as entidades mantenedoras de IES fossem constituídas, até o advento da Lei no 9.394/96 (Lei de Diretrizes e Bases da Educação Nacional - LDB) e do Decreto n ${ }^{\text {o }} 2.207 / 1997$, sob a forma de sociedade sem finalidade lucrativa. Somente após a regulamentação da LDB é que se abriu o precedente para que as mantenedoras pudessem constituir-se como sociedades comerciais (SILVA JUNIOR; MUNIZ, 2004).

Constata-se, com isso, que a presença de IES que tenham o lucro como fundamento essencial para a execução de suas atividades é um fenômeno relativamente recente, com 
aproximadamente 20 anos. Esse movimento de criação de novas IES que visavam lucro e de transformação de IES sem finalidade lucrativa em instituições com fins lucrativos ocorreu de forma mais frequente no início dos anos 2000, mesmo período em que houve um movimento de expansão do setor privado e encolhimento do setor público na educação superior brasileira.

Sobre esse movimento, Silva Junior e Muniz (2004) destacam, com base nos dados dos Censos Educacionais da época que, do ano de 1998 para o ano de 2002, o número de cursos superiores quase dobrou, saindo de 6.950 para 13.399. O número de IES teve um aumento de aproximadamente 70\% saindo de 973 IES em 1998 para 1.637 em 2002. Neste mesmo período o número de IES privadas teve crescimento de quase 90\%, saindo de 764 IES em 1998 para 1.442 IES em 2002; enquanto o número de IES públicas diminuiu em aproximadamente 9\%, saindo de 209 em 1998 para 195 em 2002.

Nesse processo de expansão no número de IES privadas, a educação superior chegou ao mercado de capitais por meio de processo de Initial Public Offering - IPO (termo em inglês que se refere a Oferta Pública Inicial) realizado pelas companhias Estácio Participações S.A. e Kroton Educacional S.A. no ano de 2007 junto à BM\&FBovespa. Esses dois processos são decorrentes da transformação respectivamente das mantenedoras da Universidade Estácio de Sá e do Pitágoras, em companhias abertas.

Nos anos seguintes, novos IPO foram realizados com a listagem da Anhanguera Educacional S.A., da GAEC Educação S.A. (ANIMA) e da Ser Educacional S.A. Assim, o setor passou a ser constituído até o ano de 2013 por cinco companhias. Em 2013, a Anhanguera Educacional S.A. foi adquirida pela Kroton Educacional S.A. fazendo com que o setor contasse com quatro companhias. Embora, o setor seja considerado pequeno em termos do quantitativo de companhias, constata-se a relevância dessas companhias em razão do porte, da movimentação financeira e do número de alunos matriculados, já destacados na introdução do artigo, justificando, com isso, a análise de suas DVA.

\section{MÉTODO}

Metodologicamente a pesquisa configura-se como um estudo de natureza quantitativa e descritiva (TRIPODI et al., 1981) por meio de uma pesquisa documental realizada junto a documentos autênticos com a finalidade de descrever e comparar fatos sociais (PÁDUA, 2004). Os dados foram coletados por meio de triangulação (DENZIN, 1989; JICK, 1979) ao articular três fontes de documentos, quais sejam, as DVA disponíveis na ferramenta 


\section{DEMONSTRAÇÃO DE VALOR ADICIONADO NA INSTITUIÇÃO DE EDUCAÇÃO SUPERIOR: \\ EVIDÊNCIAS DO MERCADO DE CAPITAIS BRASILEIRO \\ DOI: http://dx.doi.org/10.5007/1983-4535.2017v10n4p22}

Comdinheiro, os relatórios e outros documentos disponíveis nos sítios eletrônicos das companhias investigadas, bem como da BM\&FBovespa.

O período de investigação compreende os anos de 2010 a 2015, em razão da obrigatoriedade da divulgação da DVA. Neste período, cinco companhias divulgaram suas DVA, sendo que a Estácio Participações S.A., a Kroton Educacional S.A. e a Ser Educacional S.A. divulgaram em todo o período. Já a Anhanguera Educacional S.A. adquirida pela Kroton Educacional S.A. em 2013 divulgou a DVA nos anos de 2010 a 2013 e a GAEC Educação S.A. (ANIMA) divulgou a DVA de 2012 a 2015.

Considerando que o objetivo da pesquisa foi identificar como se caracteriza a geração e a distribuição de riquezas das companhias brasileira do setor educacional da BM\&FBovespa, as informações faltantes nos anos de 2010 e 2011 da GAEC Educação S.A. (ANIMA) e de 2014 e 2015 da Anhanguera Educacional S.A. não prejudicaram os resultados da pesquisa, principalmente pelo fato dos dados da Anhanguera Educacional S.A. estarem contemplados na DVA da Kroton Educacional S.A.

Com isso, no conjunto, os dados das DVA dessas cinco companhias permitiram caracterizar o setor em termos de geração e de distribuição de riquezas. Os dados foram analisados por meio de estatística descritiva dos indicadores de geração e de distribuição de riquezas.

\section{APRESENTAÇÃO DOS RESULTADOS}

Como forma de estruturar esta seção, optou-se por apresentar as DVA de todas as cinco companhias para, na sequência, apresentar a consolidação dos dados do setor. A Tabela 1 apresenta os dados da Anhanguera Educacional S.A. referente aos anos de 2010 a 2013.

Tabela 1 DVA Anhanguera Educacional S.A.

\begin{tabular}{l|c|c|c|c|c|c}
\hline Componentes da DVA & $\mathbf{2 0 1 0}$ & $\mathbf{2 0 1 1}$ & $\mathbf{2 0 1 2}$ & $\mathbf{2 0 1 3}$ & $\mathbf{2 0 1 4}$ & $\mathbf{2 0 1 5}$ \\
\hline $\begin{array}{l}\text { Valor Total a Distribuir - R\$ } \\
\text { (milhões) }\end{array}$ & 816.625 & 977.345 & $\begin{array}{c}1.237 .90 \\
3\end{array}$ & $\begin{array}{c}1.348 .46 \\
4\end{array}$ & - & - \\
\hline Pessoal - R\$ (milhões) & 405.637 & 524.090 & 616.631 & 676.535 & - & - \\
\hline $\begin{array}{l}\text { Impostos, taxas e Contribuições } \\
\text { - R\$ (milhões) }\end{array}$ & 117.913 & 193.351 & 202.458 & 225.106 & - & - \\
\hline $\begin{array}{l}\text { Rem. de Capitais de Terceiros - } \\
\text { R\$ (milhões) }\end{array}$ & 171.453 & 217.767 & 266.766 & 321.403 & - & - \\
\hline $\begin{array}{l}\text { Rem. de Capitais Próprios - R\$ } \\
\text { (milhões) }\end{array}$ & 121.622 & 42.137 & 152.048 & 125.420 & - & - \\
\hline Valor Total a Distribuir - \% & $100,00 \%$ & $100,00 \%$ & $100,00 \%$ & $100,00 \%$ & - & - \\
\hline Pessoal - \% & $49,67 \%$ & $53,62 \%$ & $49,81 \%$ & $50,17 \%$ & - & - \\
\hline
\end{tabular}




\section{DEMONSTRAÇÃO DE VALOR ADICIONADO NA INSTITUIÇÃO DE EDUCAÇÃO SUPERIOR: \\ EVIDÊNCIAS DO MERCADO DE CAPITAIS BRASILEIRO \\ DOI: http://dx.doi.org/10.5007/1983-4535.2017v10n4p22}

\begin{tabular}{l|c|c|c|c|c|c}
\hline $\begin{array}{l}\text { Impostos, taxas e Contribuições } \\
-\%\end{array}$ & $14,44 \%$ & $19,78 \%$ & $16,35 \%$ & $16,69 \%$ & - & - \\
\hline $\begin{array}{l}\text { Rem. de Capitais de Terceiros - } \\
\%\end{array}$ & $21,00 \%$ & $22,28 \%$ & $21,55 \%$ & $23,83 \%$ & - & - \\
\hline Rem. de Capitais Próprios - $\%$ & $14,89 \%$ & $4,31 \%$ & $12,28 \%$ & $9,30 \%$ & - & - \\
\hline
\end{tabular}

Fonte: Dados da pesquisa.

Conforme já explicitado anteriormente, a DVA da Anhanguera Educacional S.A. foi publicado até o ano de 2013, quando houve o processo de aquisição pela Kroton Educacional S.A. Os dados evidenciam um crescimento constante ao longo dos anos na geração e na distribuição de riqueza da companhia. Esse aspecto enaltece o crescimento da educação superior junto ao mercado de capitais brasileiro. A Tabela 2 a seguir apresenta os dados da DVA da GAEC Educação S.A. (ANIMA) para o período de 2012 a 2015.

Tabela 2 DVA GAEC Educação S.A. (ANIMA)

\begin{tabular}{l|c|c|c|c|c|c}
\hline \multicolumn{1}{c|}{ Componentes da DVA } & $\mathbf{2 0 1 0}$ & $\mathbf{2 0 1 1}$ & $\mathbf{2 0 1 2}$ & $\mathbf{2 0 1 3}$ & $\mathbf{2 0 1 4}$ & $\mathbf{2 0 1 5}$ \\
\hline $\begin{array}{l}\text { Valor Total a Distribuir - R\$ } \\
\text { (milhões) }\end{array}$ & - & - & 246.415 & 373.148 & 588.753 & 670.761 \\
\hline Pessoal - R\$ (milhões) & - & - & 139.725 & 225.863 & 297.460 & 383.102 \\
\hline $\begin{array}{l}\text { Impostos, taxas e Contribuições } \\
\text { - R\$ (milhões) }\end{array}$ & - & - & 39.171 & 50.297 & 60.905 & 102.606 \\
\hline $\begin{array}{l}\text { Rem. de Capitais de Terceiros - } \\
\text { R\$ (milhões) }\end{array}$ & - & - & 44.016 & 62.968 & 71.294 & 120.850 \\
\hline $\begin{array}{l}\text { Rem. de Capitais Próprios - R\$ } \\
\text { (milhões) }\end{array}$ & - & - & 23.503 & 34.020 & 159.094 & 64.203 \\
\hline $\begin{array}{l}\text { Valor Total a Distribuir - \% } \\
\text { Pessoal - \% }\end{array}$ & - & - & $100,00 \%$ & $100,00 \%$ & $100,00 \%$ & $100,00 \%$ \\
\hline $\begin{array}{l}\text { Impostos, taxas e Contribuições } \\
-\%\end{array}$ & - & - & $15,90 \%$ & $13,48 \%$ & $10,34 \%$ & $15,30 \%$ \\
\hline $\begin{array}{l}\text { Rem. de Capitais de Terceiros - } \\
\%\end{array}$ & - & - & $17,86 \%$ & $16,87 \%$ & $12,11 \%$ & $18,02 \%$ \\
\hline Rem. de Capitais Próprios - \% & - & - & $9,54 \%$ & $9,12 \%$ & $27,02 \%$ & $9,57 \%$ \\
\hline
\end{tabular}

Fonte: Dados da pesquisa.

A análise da DVA da GAEC Educação S.A. (ANIMA) indica um crescimento de aproximadamente $173 \%$ na geração e na distribuição de riquezas da companhia no período de quatro anos. Semelhante ao que ocorreu com a DVA da Anhanguera Educacional S.A., o stakeholder ao qual teve a maior parcela na distribuição de riqueza foi o quadro de funcionário (pessoal) da companhia. A Tabela 3 a seguir apresenta os dados da DVA da Estácio Participações S.A. para todo o período investigado. 


\section{DEMONSTRAÇÃO DE VALOR ADICIONADO NA INSTITUIÇÃO DE EDUCAÇÃO SUPERIOR: \\ EVIDÊNCIAS DO MERCADO DE CAPITAIS BRASILEIRO \\ DOI: http://dx.doi.org/10.5007/1983-4535.2017v10n4p22}

Tabela 3 DVA Estácio Participações S.A.

\begin{tabular}{l|c|c|c|c|c|c}
\hline \multicolumn{1}{c|}{ Componentes da DVA } & $\mathbf{2 0 1 0}$ & $\mathbf{2 0 1 1}$ & $\mathbf{2 0 1 2}$ & $\mathbf{2 0 1 3}$ & $\mathbf{2 0 1 4}$ & $\mathbf{2 0 1 5}$ \\
\hline $\begin{array}{l}\text { Valor Total a Distribuir - R\$ } \\
\text { (milhões) }\end{array}$ & 831.364 & 905.142 & $\begin{array}{c}1.079 .94 \\
0\end{array}$ & $\begin{array}{c}1.387 .25 \\
7\end{array}$ & $\begin{array}{c}1.981 .98 \\
2\end{array}$ & $\begin{array}{c}2.434 .56 \\
6\end{array}$ \\
\hline Pessoal - R\$ (milhões) & 493.815 & 529.961 & 597.730 & 725.069 & 997.503 & $\begin{array}{c}1.130 .82 \\
1\end{array}$ \\
\hline $\begin{array}{l}\text { Impostos, taxas e Contribuições } \\
\text { - R\$ (milhões) }\end{array}$ & 136.325 & 171.280 & 198.311 & 233.017 & 294.044 & 366.170 \\
\hline $\begin{array}{l}\text { Rem. de Capitais de Terceiros - } \\
\text { R\$ (milhões) }\end{array}$ & 120.564 & 133.746 & 174.212 & 184.464 & 264.790 & 452.901 \\
\hline $\begin{array}{l}\text { Rem. de Capitais Próprios - R\$ } \\
\text { (milhões) }\end{array}$ & 80.660 & 70.155 & 109.687 & 244.707 & 425.645 & 484.674 \\
\hline Valor Total a Distribuir - \% & $100,00 \%$ & $100,00 \%$ & $100,00 \%$ & $100,00 \%$ & $100,00 \%$ & $100,00 \%$ \\
\hline Pessoal - \% & $59,40 \%$ & $58,55 \%$ & $55,35 \%$ & $52,27 \%$ & $50,33 \%$ & $46,45 \%$ \\
\hline $\begin{array}{l}\text { Impostos, taxas e Contribuições } \\
-\%\end{array}$ & $16,40 \%$ & $18,92 \%$ & $18,36 \%$ & $16,80 \%$ & $14,84 \%$ & $15,04 \%$ \\
\hline $\begin{array}{l}\text { Rem. de Capitais de Terceiros - } \\
\%\end{array}$ & $14,50 \%$ & $14,78 \%$ & $16,13 \%$ & $13,30 \%$ & $13,36 \%$ & $18,60 \%$ \\
\hline Rem. de Capitais Próprios - \% & $9,70 \%$ & $7,75 \%$ & $10,16 \%$ & $17,64 \%$ & $21,48 \%$ & $19,91 \%$ \\
\hline
\end{tabular}

Fonte: Dados da pesquisa.

A DVA da Estácio Participações S.A., no período de seis anos, teve um aumento de aproximadamente 200\%. Observa-se nesta DVA a mesma tendência de maior distribuição da parcela da riqueza para os funcionários (pessoal) da companhia. A Tabela 4 a seguir apresenta os dados da DVA da Kroton Educacional S.A. para todo o período investigado.

Tabela 4 DVA Kroton Educacional S.A.

\begin{tabular}{l|c|c|c|c|c|c}
\hline \multicolumn{1}{c|}{ Componentes da DVA } & $\mathbf{2 0 1 0}$ & $\mathbf{2 0 1 1}$ & $\mathbf{2 0 1 2}$ & $\mathbf{2 0 1 3}$ & $\mathbf{2 0 1 4}$ & $\mathbf{2 0 1 5}$ \\
\hline $\begin{array}{l}\text { Valor Total a Distribuir - R\$ } \\
\text { (milhões) }\end{array}$ & 398.815 & 533.673 & $\begin{array}{c}1.054 .42 \\
2\end{array}$ & $\begin{array}{c}1.475 .21 \\
1\end{array}$ & $\begin{array}{c}2.922 .59 \\
0\end{array}$ & $\begin{array}{c}4.181 .33 \\
8\end{array}$ \\
\hline Pessoal - R\$ (milhões) & 327.915 & 375.400 & 507.456 & 642.581 & $\begin{array}{c}1.190 .66 \\
3\end{array}$ & $\begin{array}{c}1.621 .19 \\
8\end{array}$ \\
\hline $\begin{array}{l}\text { Impostos, taxas e Contribuições } \\
\text { - R\$ (milhões) }\end{array}$ & 21.114 & 29.959 & 160.171 & 206.273 & 350.776 & 582.507 \\
\hline $\begin{array}{l}\text { Rem. de Capitais de Terceiros - } \\
\text { R } \text { (milhões) }\end{array}$ & 79.409 & 90.939 & 184.751 & 109.786 & 380.551 & 581.499 \\
\hline $\begin{array}{l}\text { Rem. de Capitais Próprios - R\$ } \\
\text { (milhões) }\end{array}$ & -29.623 & 37.375 & 202.044 & 516.571 & $\begin{array}{c}1.000 .60 \\
0\end{array}$ & $\begin{array}{c}1.396 .13 \\
4\end{array}$ \\
\hline Valor Total a Distribuir - \% & $100,00 \%$ & $100,00 \%$ & $100,00 \%$ & $100,00 \%$ & $100,00 \%$ & $100,00 \%$ \\
\hline Pessoal - \% & $76,54 \%$ & $70,34 \%$ & $48,13 \%$ & $43,56 \%$ & $40,74 \%$ & $38,77 \%$ \\
\hline $\begin{array}{l}\text { Impostos, taxas e Contribuições } \\
-\%\end{array}$ & $4,93 \%$ & $5,61 \%$ & $15,19 \%$ & $13,98 \%$ & $12,00 \%$ & $13,93 \%$ \\
\hline $\begin{array}{l}\text { Rem. de Capitais de Terceiros - } \\
\text { \% }\end{array}$ & $18,53 \%$ & $17,04 \%$ & $17,52 \%$ & $7,44 \%$ & $13,02 \%$ & $13,91 \%$ \\
\hline Rem. de Capitais Próprios - \% & $-6,91 \%$ & $7,00 \%$ & $19,16 \%$ & $35,02 \%$ & $34,24 \%$ & $33,39 \%$ \\
\hline
\end{tabular}

Fonte: Dados da pesquisa. 


\section{DEMONSTRAÇÃO DE VALOR ADICIONADO NA INSTITUIÇÃO DE EDUCAÇÃO SUPERIOR: \\ EVIDÊNCIAS DO MERCADO DE CAPITAIS BRASILEIRO \\ DOI: http://dx.doi.org/10.5007/1983-4535.2017v10n4p22}

O maior crescimento na geração e na distribuição de riqueza dentre as cinco companhias analisadas foi o da Kroton Educacional S.A., com um percentual aproximado de $950 \%$ no período investigado. Aparentemente, esse maior aumento está relacionado ao fato da Kroton S.A. ter adquirido em 2013 a Anhanguera Educacional S.A., incorporando com isso, a partir do ano de 2014, a geração e distribuição de riquezas daquela companhia.

Um outro aspecto a ser observado na DVA da Kroton Educacional S.A. é que em 2010 a remuneração de capital próprio foi negativa. Esse aspecto indica que a companhia teve prejuízo neste ano e, com isso, destruiu valor para o acionista. A Tabela 5 a seguir apresenta os dados da DVA da Ser Educacional S.A. para todo o período investigado

Tabela 5 DVA Ser Educacional S.A.

\begin{tabular}{l|c|c|c|c|c|c}
\multicolumn{1}{c|}{ Componentes da DVA } & $\mathbf{2 0 1 0}$ & $\mathbf{2 0 1 1}$ & $\mathbf{2 0 1 2}$ & $\mathbf{2 0 1 3}$ & $\mathbf{2 0 1 4}$ & $\mathbf{2 0 1 5}$ \\
\hline $\begin{array}{l}\text { Valor Total a Distribuir - R\$ } \\
\text { (milhões) }\end{array}$ & 110.710 & 136.783 & 202.402 & 383.159 & 622.141 & 856.165 \\
\hline Pessoal - R\$ (milhões) & 53.646 & 74.900 & 102.141 & 170.355 & 261.029 & 468.096 \\
\hline $\begin{array}{l}\text { Impostos, taxas e Contribuições } \\
\text { - R } \$ \text { (milhões) }\end{array}$ & 1.752 & 3.296 & 4.510 & 30.480 & 56.474 & 59.745 \\
\hline $\begin{array}{l}\text { Rem. de Capitais de Terceiros - } \\
\text { R\$ (milhões) }\end{array}$ & 19.593 & 27.035 & 31.495 & 66.027 & 90.774 & 167.259 \\
\hline $\begin{array}{l}\text { Rem. de Capitais Próprios - R\$ } \\
\text { (milhões) }\end{array}$ & 35.719 & 31.552 & 64.256 & 116.297 & 213.864 & 161.065 \\
\hline Valor Total a Distribuir - \% & $100,00 \%$ & $100,00 \%$ & $100,00 \%$ & $100,00 \%$ & $100,00 \%$ & $100,00 \%$ \\
\hline Pessoal - \% & $48,46 \%$ & $54,76 \%$ & $50,46 \%$ & $44,46 \%$ & $41,96 \%$ & $54,67 \%$ \\
\hline $\begin{array}{l}\text { Impostos, taxas e Contribuições } \\
-\%\end{array}$ & $1,58 \%$ & $2,41 \%$ & $2,23 \%$ & $7,95 \%$ & $9,08 \%$ & $6,98 \%$ \\
\hline $\begin{array}{l}\text { Rem. de Capitais de Terceiros - } \\
\%\end{array}$ & $17,70 \%$ & $19,76 \%$ & $15,56 \%$ & $17,23 \%$ & $14,59 \%$ & $19,54 \%$ \\
\hline Rem. de Capitais Próprios - \% & $32,26 \%$ & $23,07 \%$ & $31,75 \%$ & $30,35 \%$ & $34,38 \%$ & $18,81 \%$ \\
\hline
\end{tabular}

Fonte: Dados da pesquisa.

A Ser Educacional S.A. obteve no período analisado um aumento de aproximadamente $675 \%$ na geração e na distribuição de riquezas. A DVA desta companhia consolida a tendência de maior distribuição da riqueza para os funcionários (pessoal). A Tabela 6 a seguir apresenta os dados consolidados da DVA do setor de educação superior para todo o período investigado. 


\section{DEMONSTRAÇÃO DE VALOR ADICIONADO NA INSTITUIÇÃO DE EDUCAÇÃO SUPERIOR: \\ EVIDÊNCIAS DO MERCADO DE CAPITAIS BRASILEIRO \\ DOI: http://dx.doi.org/10.5007/1983-4535.2017v10n4p22}

Tabela 6 DVA do setor educacional superior na BM\&FBovespa.

\begin{tabular}{l|c|c|c|c|c|c}
\hline \multicolumn{1}{c|}{ Componentes da DVA } & $\mathbf{2 0 1 0}$ & $\mathbf{2 0 1 1}$ & $\mathbf{2 0 1 2}$ & $\mathbf{2 0 1 3}$ & $\mathbf{2 0 1 4}$ & $\mathbf{2 0 1 5}$ \\
\hline $\begin{array}{l}\text { Valor Total a Distribuir - R\$ } \\
\text { (milhões) }\end{array}$ & $\begin{array}{c}2.157 .51 \\
4\end{array}$ & $\begin{array}{c}2.552 .94 \\
3\end{array}$ & $\begin{array}{c}3.821 .08 \\
2\end{array}$ & $\begin{array}{c}4.967 .23 \\
9\end{array}$ & $\begin{array}{c}6.115 .46 \\
6\end{array}$ & $\begin{array}{c}8.142 .83 \\
0\end{array}$ \\
\hline Pessoal - R\$ (milhões) & $\begin{array}{c}1.281 .01 \\
3\end{array}$ & $\begin{array}{c}1.504 .35 \\
1\end{array}$ & $\begin{array}{c}1.963 .68 \\
3\end{array}$ & $\begin{array}{c}2.440 .40 \\
3\end{array}$ & $\begin{array}{c}2.746 .65 \\
5\end{array}$ & $\begin{array}{c}3.603 .21 \\
7\end{array}$ \\
\hline $\begin{array}{l}\text { Impostos, taxas e Contribuições } \\
\text { - R\$ (milhões) }\end{array}$ & 277.104 & 397.886 & 604.621 & 745.173 & 762.199 & $\begin{array}{c}1.111 .02 \\
8\end{array}$ \\
\hline $\begin{array}{l}\text { Rem. de Capitais de Terceiros - } \\
\text { R\$ (milhões) }\end{array}$ & 391.019 & 469.487 & 701.240 & 744.648 & 807.409 & $\begin{array}{c}1.322 .50 \\
9\end{array}$ \\
\hline $\begin{array}{l}\text { Rem. de Capitais Próprios - R\$ } \\
\text { (milhões) }\end{array}$ & 208.378 & 181.219 & 551.538 & $\begin{array}{c}1.037 .01 \\
5\end{array}$ & $\begin{array}{c}1.799 .20 \\
3\end{array}$ & $\begin{array}{c}2.106 .07 \\
6\end{array}$ \\
\hline Valor Total a Distribuir - \% & $100,00 \%$ & $100,00 \%$ & $100,00 \%$ & $100,00 \%$ & $100,00 \%$ & $100,00 \%$ \\
\hline Pessoal - \% & $59,37 \%$ & $58,93 \%$ & $51,39 \%$ & $49,13 \%$ & $44,91 \%$ & $44,25 \%$ \\
\hline $\begin{array}{l}\text { Impostos, taxas e Contribuições } \\
-\%\end{array}$ & $12,84 \%$ & $15,59 \%$ & $15,82 \%$ & $15,00 \%$ & $12,46 \%$ & $13,64 \%$ \\
\hline $\begin{array}{l}\text { Rem. de Capitais de Terceiros - } \\
\%\end{array}$ & $18,12 \%$ & $18,39 \%$ & $18,35 \%$ & $14,99 \%$ & $13,20 \%$ & $16,24 \%$ \\
\hline Rem. de Capitais Próprios - \% & $9,66 \%$ & $7,10 \%$ & $14,43 \%$ & $20,88 \%$ & $29,42 \%$ & $25,86 \%$ \\
\hline
\end{tabular}

Fonte: Dados da pesquisa.

Ao se analisar os resultados do conjunto das DVA das companhias do setor constatase um crescimento de aproximadamente $280 \%$ na geração e na distribuição de riquezas no setor de educação superior, alcançando a geração de 8,1 bilhões de reais em riqueza no ano de 2015 representando $0,15 \%$ do Produto Interno Bruto (PIB) brasileiro que foi de 5,9 trilhões de reais. Constata-se ainda que na média, a distribuição de riquezas entre os agentes que contribuíram para a sua geração, assume a seguinte configuração: (1) em primeiro lugar os funcionários (pessoal) com o percentual médio de 51,33\%; (2) em segundo lugar a remuneração de capital próprio com um percentual médio de 17,89\%; (3) seguido da remuneração de capital de terceiros com um percentual médio de $16,55 \%$; e (4) em quarto e por último os impostos, taxas e contribuições com o percentual médio de 14,23\%.

\section{DISCUSSÃO DOS RESULTADOS}

O conjunto de resultados da pesquisa permite uma série de análises e reflexões acerca da RSC, da relação entre as companhias e seus stakeholders, da relevância da DVA no papel de evidenciação da geração e da distribuição de riqueza das companhias, bem como da presença de IES no mercado de capitais brasileiro. Do ponto de vista da RSC, os resultados permitem reflexões acerca do papel social de companhias (XAVIER; MARANHÃO, 2010; FARIA; SAUERBRONN, 2008) que operam em um contexto permeado por contradições. 
Essas contradições dizem respeito, de um lado, à concepção de educação tradicionalmente adotada no Brasil e, de outro, à natureza das companhias que operam no mercado de capitais. Conforme aponta Dias Sobrinho (2013), historicamente, os valores institucionais que conceberam a educação superior no Brasil a trataram como um "bem público" e um "direito social”, por ter como finalidade essencial a formação de sujeitos e, por consequência, o aprofundamento da cidadania e da democratização da sociedade. Silva Junior e Silva (2013) complementam esse entendimento ao indicar que, por se tratar de um "bem público" a educação superior não pode ser tratada como uma "mercadoria" a ser comercializada. Porém, o que se observa na prática corporativa das companhias presentes no mercado de capitais que a essência de suas atividades é a obtenção de lucro por meio da produção e/ou comercialização de bens e/ou serviços (FRIEDMAN, 2014).

A despeito dessas contradições, observa-se nos resultados uma convergência em relação ao ponto de vista de Parmar et al. (2010). Para esses autores é relevante que a gestão corporativa considere os interesses dos stakeholders, mesmo sob a possibilidade de minimizar o retorno para os acionistas. Na análise das DVA dessas companhias, pode-se constatar que o acionista não foi o principal agente a ser contemplado com a distribuição de riqueza.

Nesse sentido, os resultados parecem indicar que a visão que explica o interesse dessas companhias pela RSC é a de natureza estratégica que prega a maximização dos stakeholders (JAH; COX, 2015). Segundo esta visão, há por parte dos gestores das companhias interesse em manter melhores relações com outros stakeholders (DENG; KANG; LOW, 2013), fazendo com que a governança socialmente responsável esteja vocacionada para eles, e não meramente para os acionistas (BARET, 2006; GOND; MULLENBACH-SERVAYRE, 2004).

Em parte, a aderência dessa visão explicativa para esse comportamento dessas companhias pode estar relacionada às características do mercado de capitais brasileiro que é constituído predominantemente por companhias cuja propriedade é concentrada e com presença de relações familiares no conselho de administração (LEAL; BORTOLON 2009; SARLO NETO et al. 2005; KPMG 2016). Com essas características, essas companhias possuem uma relação de sobreposição entre a estrutura de propriedade e a de gestão que culmina no alinhamento de interesses entre o acionista e o gestor, fazendo com que a maximização dos stakeholders seja uma resultante da estratégia (JAH; COX, 2015), possivelmente para legitimar e/ou minimizar os efeitos da contradição entre a concepção de 
educação no Brasil e a finalidade lucrativa das corporações (DIAS SOBRINHO, 2013; SILVA JUNIOR; SILVA, 2013; FRIEDMAN, 2014).

No que tange a DVA, observa-se que essa demonstração cumpre o seu papel informacional de evidenciar a geração e a distribuição de riquezas das companhias (MACHADO; MACEDO; MACHADO, 2015; HALLER; STATEN, 2014). Ainda, o fato dessa demonstração ser obrigatória por força da Lei $n^{0}$ 11.638/2007 e padronizada por meio do Pronunciamento Técnico CPC-09 (CPC, 2009), permite, entre outros aspectos, a comparabilidade e credibilidade das informações contábeis (MACHADO, 2010). Nesse aspecto, a DVA, a despeito de ser uma das vertentes do balanço social (CPC, 2008; SANTOS, 2007; IUDÍCIBUS et al. 2003), se diferencia do balanço social pelo fato deste ser considerado um disclosure voluntário e não padronizado (NOVELINI; FREGONESI, 2013; MILANI FILHO, 2008).

A análise da DVA realizada neste estudo alinha-se mais com o método direto apontado por Haller e Staten (2014) por concentrar-se mais na distribuição de riquezas geradas na economia, indicando que a medida macroeconômica da DVA coloca a atividade econômica da companhia dentro do seu contexto social. Nesse sentido, o foco central da análise volta-se para a distribuição da riqueza entre os agentes (sociais e econômicos) que contribuíram para a sua geração, quais sejam, funcionários (ou pessoal), governo, financiadores e detentores do capital (MACHADO; MACEDO; MACHADO, 2015; CPC, 2009).

A síntese dos resultados indica que todas as companhias analisadas geraram aproximadamente 8,1 bilhões de reais em riquezas no ano de 2015. Deste total, 3,6 bilhões foi distribuído para funcionários (pessoal); 1,1 bilhão para o governo por meio de tributos; 1,3 bilhão para financiadores e 2,1 bilhões para os acionistas. Em parte, esses resultados são coerentes com os serviços prestados por essas companhias - educação superior.

Conforme apontam Silva Junior e Muniz (2004), a educação superior abrange atividades de ensino, pesquisa e extensão que envolve respectivamente a transmissão, o desenvolvimento e a aplicação de conhecimento, razão pela qual as organizações que atuam no setor educacional superior são intensivas em conhecimento (SILVA JUNIOR; POLIZEL; SILVA, 2012). Com isso, considerando que a gestão do conhecimento é uma atividade eminentemente humana e que articula os níveis de conhecimento tácito e explícito (NONAKA; TAKEUCHI, 2008), era esperado que a maior parcela de distribuição de riquezas 
fosse para os funcionários (pessoal) que são os docentes, técnicos administrativos e gestores universitários.

Além desse aspecto, destaca-se que a menor parcela de riqueza distribuída foi para o governo por meio de pagamento de tributos que representam a remuneração pela estrutura social, política e econômica que propiciam as condições fundamentais para as operações da companhia (MACHADO; MACEDO; MACHADO, 2015; CPC, 2008). Essa menor parcela para o governo remete a uma reflexão sobre a atuação de outras modalidades de IES (SILVA JUNIOR; MUNIZ, 2004), como por exemplo, as instituições sem finalidade lucrativa.

Enquanto essas companhias listadas na BM\&FBovespa participantes do "Novo Mercado" são auditadas e tem a obrigatoriedade de transparência na divulgação de informações ao mercado e à sociedade, as instituições sem fins lucrativos operam em um contexto que prima pela ausência de transparência e de obrigatoriedade de prestar informações à sociedade. Acredita-se que esse aspecto seja paradoxal, pelo fato dessas instituições gozarem de isenção tributária e serem omissas em prestar contas à sociedade de suas ações. Diferentemente, as companhias presentes no mercado de capitais, recolhem tributos, contribuem para o bem-estar social (LEAL JUNIOR, 2011; CARDOSO, 2011; RIBEIRO; GESTEIRO, 2006) e ainda prestam contas de seus atos à sociedade.

\section{CONCLUSÕES}

A proposta deste estudo foi verificar como ocorre a geração e a distribuição de riquezas de IES brasileiras que se configuram como companhias abertas listadas BM\&FBovespa. Para isso, realizou-se uma pesquisa documental de natureza quantitativa e descritiva junto a DVA e outros documentos disponibilizados nos sites das companhias, da BM\&FBovespa e na base de dados da ferramenta Comdinheiro (TRIPODI et al., 1981; PÁDUA, 2004). Foram coletados dados junto a cinco companhias que compõem o setor educacional superior no mercado de capitais brasileiro no período de 2010 a 2015.

Como síntese dos resultados, constatou-se que no período de seis anos o setor gerou aproximadamente 27,8 bilhões de riqueza, assim distribuída: (1) 13,6 bilhões foi distribuído para funcionários (pessoal); (2) 3,9 bilhões para o governo por meio de tributos; (3) 4,4 bilhões para financiadores; e, (4) 5,9 bilhões para os acionistas. Os resultados apontam a relevância do setor, que embora pequeno em termos do número de companhias, é significativo 


\section{DEMONSTRAÇÃO DE VALOR ADICIONADO NA INSTITUIÇÃO DE EDUCAÇÃO SUPERIOR: \\ EVIDÊNCIAS DO MERCADO DE CAPITAIS BRASILEIRO \\ DOI: http://dx.doi.org/10.5007/1983-4535.2017v10n4p22}

em termos de receita gerada e de número de alunos matriculados (ESTACIO, 2016; GAEC EDUCAÇÃO, 2016; KROTON, 2016; SER EDUCACIONAL, 2016; INEP, 2015).

A maior parcela de riqueza distribuída foi para os funcionários (pessoal), indicando coerência em termos dos resultados esperados. Considerando a natureza da atividade dessas companhias (educação superior) ser intensiva em conhecimento, era esperado que o corpo docente, técnico administrativo e de gestores universitários ficassem efetivamente com a maior parcela da riqueza gerada, pois, foram eles que mais contribuíram para a sua geração (SILVA JUNIOR; POLIZEL; SILVA, 2012; NONAKA; TAKEUCHI, 2008; SILVA JUNIOR; MUNIZ, 2004).

Dos resultados alcançados com esta pesquisa, dois pontos centrais de reflexão merecem atenção. O primeiro refere-se à relação paradoxal entre a concepção de educação superior presente no Brasil e a natureza lucrativa das companhias que atuam no mercado de capitais (DIAS SOBRINHO, 2013; SILVA JUNIOR; SILVA, 2013; FRIEDMAN, 2014). Esse aspecto está relacionado ao fato das companhias presentes no mercado de capitais tratarem a educação como um comércio, atuarem em um contexto em que o marco regulatório trate a educação com um "bem-público" e um direito do povo (DIAS SOBRINHO, 2013; SILVA JUNIOR; SILVA, 2013). Essa relação paradoxal culmina, entre outros aspectos, no debate entre a educação superior pública e a privada e a qualidade dos serviços educacionais prestados. Nesse aspecto, o sistema de avaliação operacionalizado pelo Instituto Nacional de Estudos e Pesquisas Educacionais Anísio Teixeira (INEP) tem indicado que a educação pública, com menor representatividade, possui melhores indicadores avaliativos quando comparado com a educação privada. Assim, parece haver um direcionamento das políticas públicas para a educação superior no Brasil de transferir a responsabilidade da educação superior para a iniciativa privada, mesmo que isso comprometa a qualidade dos serviços educacionais prestados à sociedade brasileira. Em outros termos, a opção do governo brasileiro tem sido de abrir mão da oferta da educação superior, transferindo-a para o setor privado, mesmo que isso comprometa a qualidade da formação educacional do cidadão, ou seja, a decisão tem sido de proporcionar ao povo brasileiro uma educação superior paga e de pior qualidade (quando comparado com a educação pública, gratuita e de melhor qualidade).

O segundo ponto central refere-se à relação tributária e de transparência que envolve a atuação das companhias e das instituições na educação superior brasileira. Enquanto as companhias pertencentes ao mercado financeiro recolhem tributos ao Estado e possuem uma 
gestão corporativa transparente na divulgação de informações ao mercado e à sociedade; as instituições sem fins lucrativos (algumas delas filantrópicas e confessionais) são isentas de pagamentos de tributos e possuem uma gestão institucional permeada pela ausência de transparência (LEAL JUNIOR, 2011; CARDOSO, 2011; RIBEIRO; GESTEIRO, 2006; SILVA JUNIOR; MUNIZ, 2004). Esse aspecto remete a uma reflexão acerca da viabilidade deste regime tributário de isenção de tributos sem controle e cobranças governamentais acerca da atuação das IES sem fins lucrativos.

O estudo apresenta como principal limitação o fato de ter realizado uma pesquisa documental em um único setor. Em razão disso, seria relevante desenvolver uma investigação qualitativa por meio de estudo de casos múltiplos junto as companhias do setor, com vista a um maior aprofundamento na investigação acerca da RSC e de indicadores de desempenho socialmente responsáveis. Outra possibilidade seria de comparar a DVA do setor educacional superior com outros setores da BM\&FBovespa. Espera-se que os resultados desta pesquisa, bem como as considerações e reflexões realizadas, contribuam para que a comunidade acadêmica em geral, gestores universitários e responsáveis pelas políticas públicas voltadas para a educação superior pensem e repensem a questão da RSC no âmbito da educação superior brasileira.

\section{REFERÊNCIAS}

BARET, P. L'évaluation contingente de la performance globale des entreprises: une méthode pour fonder un management sociétalement responsable? In: ROSE, J-J. (Ed). Responsabilité sociale de l'entreprise, pour un nouveau contrat social. Bruxelles: De Boeck \& Larcier, 2006. p. 135-152.

BOLSA VAlORES, MERCADORIAS E FUTUROS DE SÃO PAULO. Produtos. Empresas listadas. São Paulo, 2016. Disponível em:

$<$ http://www.bmfbovespa.com.br/pt_br/produtos/listados-a-vista-e-derivativos/rendavariavel/empresas-listadas.htm>. Acesso em: 19 jun. 2016.

BORTOLON, P. M.; SILVA JUNIOR, A. da. Delisting brazilian public companies: empirical evidence about corporate governance issues. Brazilian Business Review, BBR Special Issues, Vitória, p. 92-117, 2015. doi: 10.15728/bbrconf.2015.5.

CALLAN, S. J.; THOMAS, J. M., Corporate financial performance and corporate social performance: an update and reinvestigation. Corporate Social Responsibility and Environmental Management, [S.1.], v.16, n. 2, p. 61-78, 2009.

CARDOSO, A. da S. A função social do tributo na perspectiva da solidariedade. Revista Direito Mackenzie, São Paulo, v. 5, n. 2, p. 10-20, 2011. 
COMITÊ DE PRONUNCIAMENTOS CONTÁBEIS (CPC). Pronunciamento técnico CPC09: demonstração do valor adicionado. Brasília. Comitê de Pronunciamentos Contábeis, 2008. CRONQVIST, H. et al. Do entrenched managers pay their workers more? The Journal of Finance, [S.1.], v. 64, n.1, p. 309-339, 2009.

DENG, X., KANG, J-K.; LOW, B. S. Corporate social responsibility and stakeholder value maximization: evidence from mergers. Journal of Financial Economics, [S.1.], v. 110, n.1, p. 87-109, 2013..

DENZIN, N. The research act: a theoretical introduction to sociological methods. 3. ed. Prentice Hall, New York, NY, 1989..

DIAS SOBRINHO, J. Educação superior: bem público, equidade e democratização. Avaliação, Campinas; Sorocaba, SP, v. 18, n. 1, p. 107-126, mar. 2013.

DUPAS, G. Atores e poderes na nova ordem global: assimetrias, instabilidades e imperativos de legitimação. São Paulo: UNESP, 2005.

ESTÁCIO PARTICIPAÇÕES. Informações financeiras. Resultados trimestrais. Rio de Janeiro, 2016. Disponível em:

$<$ http://www.estacioparticipacoes.com.br/estacio2010/web/conteudo_pt.asp?idioma=0\&conta $=28 \&$ tipo $=30230>$. Acesso em: 19 jun. 2016 .

FARIA, A.; SAUERBRONN, F. F. a responsabilidade social é uma questão de estratégia? uma abordagem crítica. Revista de Administração Pública, Rio de Janeiro, v. 42, n. 1, p. 733, 2008.

FRIEDMAN, M. Capitalismo e liberdade. São Paulo: LTC, 2014.

GAEC EDUCAÇÃO. Informações financeiras. Resultados trimestrais. São Paulo, 2016.

Disponível em:

$<$ http://ri.animaeducacao.com.br/anima/web/conteudo_pt.asp?idioma $=0 \&$ conta $=28 \&$ tipo $=490$ 66>. Acesso em: 19 jun. 2016.

GATSIOS, R. C. et al. Impacto da adoção do padrão IFRS sobre custo de capital próprio das empresas de capital aberto no Brasil. In: CONGRESSO USP CONTABILIDADE E CONTROLADORIA, 15., 2015, São Paulo. Anais.... São Paulo: FIPECAFI, 2015.

GOND J-P.; MULLENBACH-SERVAYRE, A. Les fondements théoriques de la responsabilité sociétale de l'entreprise. La Revue des Sciences de Gestion: Direction et Gestion, Paris, n. 205, p. 93-116, 2004

HALLER, A.; STATEN, C. V. The value added statement: an appropriate instrument for integrated reporting. Accounting, Auditing \& Accountability Journal, [S.1.], v. 27, n. 7, p. 1190-1216, 2014.

INSTITUTO NACIONAL DE ESTUDOS E PESQUISAS EDUCACIONAIS ANÍSIO TEIXEIRA. Censo da educação superior 2013: resumo técnico. Brasília: INEP, 2015. 
IUDÍCIBUS, S. et al. Manual de contabilidade das sociedades por ações. 6. ed. São Paulo: Atlas, 2003.

JAH, A.; COX, J. Corporate social responsibility and social capital. Journal of Banking \& Finance, [S.1.], v. 60, p.252-270, 2015.

JICK, T. D. Mixing qualitative and quantitative methods: triangulation in action. Administrative Science Quarterly, [S.1.], v.24, n.4, 1979.

KEMPER, J. et al. Competition-motivated corporate social responsibility. Journal of Business Research, [S.1.], v. 66, n. 10, p.1954-1963, 2013.

KPMG. A governança corporativa e o mercado de capitais: um panorama atual das empresas abertas, com base nos seus Formulários de Referência - 2014-2015. Disponível em:

$<$ https://www.kpmg.com/BR/PT/Estudos_Analises/artigosepublicacoes/Documents/Advisory/ Governanca-Corporativa-Mercado-Capitais-14-15.pdf.>. Acesso em: 19 jul. 2016.

KROTON PARTICIPAÇÕES. Central de resultados. Release de resultados trimestrais. São Paulo, 2016. Disponível em: <http://www.kroton.com.br/>. Acesso em: 19 jun. 2016.

LEAL, R. P. C.; BORTOLON, P. M. Controle compartilhado: impactos sobre o valor da firma. In: INSTITUTO BRASILEIRO DE GOVERNANÇA CORPORATIVA (Orgs.). Governança corporativa: estrutura de controles societários. São Paulo: Saint Paul Editora, 2009, p.125-137.

LEAL JUNIOR, J. C. Da relevância da atividade empresarial no cenário social e jurídico brasileiro. Revista Espaço Acadêmico, Maringá, v. 11, n. 124, p. 48-56, 2011.

LOHN, V. M. Indicadores de responsabilidade social: uma proposta para as instituições de ensino superior. Revista Gestão Universitária na América Latina - GUAL, Florianópolis, v. 4, n. 1, p. 110-128, 2011.

MACHADO, M. A. V.; MACEDO, M. A. da S.; MACHADO, M. R. Análise da relevância do conteúdo informacional da DVA no mercado brasileiro de capitais. Revista Contabilidade \& Finanças - USP, São Paulo, v. 26, n. 67, p. 57-69, 2015.

MACHADO, M. R. As informações sociais e ambientais evidenciadas nos relatórios anuais das empresas: a percepção dos usuários. 2010. 159 f. Tese (Doutorado em Ciência Contábeis) - Faculdade de Economia, Administração e Contabilidade, Universidade de São Paulo, São Paulo, 2010

MAZZIONI, S. et al. Análise dos indicadores de valor adicionado de fundações educacionais de Santa Catarina. In: COLÓQUIO INTERNACIONAL SOBRE GESTÃO UNIVERSITÁRIA NAS AMÉRICAS, 14., 2014, Florianópolis. Anais..., Florianópolis: INPEAU, 2005. 
MAZZIONI, S.; TINOCO, J. E. P.; OLIVEIRA, A. B. S. Proposta de um modelo de balanço social para fundações universitárias. Base - Revista de Administração e Contabilidade da Unisinos, São Leopoldo, v. 4, n. 3, p. 274-286, 2007.

MILANI FILHO, M. A. F. Responsabilidade social e investimento privado: entre o discurso e a evidenciação. Revista Contabilidade \& Finanças - USP, São Paulo, v. 19, n. 47, p. $89-101,2008$.

NÓBREGA, M. da et al. O mercado de capitais: sua importância para o desenvolvimento e os entraves com que se defronta o Brasil (Estudos para o Desenvolvimento do Mercado de Capitais da BOVESPA). São Paulo: BM\&FBovespa, 2000.

NOGUEIRA, M. da G. S. S.; GARCIA, T. E. M.; RAMOS, M. da G. G. Governança corporativa, responsabilidade social corporativa: a visão de atores de uma Instituição de Ensino Superior - IES federal. Revista Gestão Universitária na América Latina - GUAL, Florianópolis, v. 5, n. 3, p. 222-244, 2012.

NONAKA, I.; TAKEUCHI, H. Criação e dialética do conhecimento. In: . Gestão do conhecimento. Tradução de Ana Thorell. Porto Alegre: Bookman, 2008.

NOVELINI, C. P.; FREGONESI, M. F. S. A. Análise da divulgação de informações sobre investimentos sociais por empresas que se declaram socialmente responsáveis. Revista de Contabilidade e Organizações - USP, São Paulo, v. 7, n. 17, p. 90-101, 2013.

OLIVEIRA, M. V. de et al. O marketing social em projetos de responsabilidade social universitária. Revista Gestão Universitária na América Latina - GUAL, Florianópolis, v. 8, n. 2, p. 113-137, 2015.

PÁDUA, E. M. M. de. Metodologia da pesquisa: abordagem teórico-prática. 10. ed. rev. e atual. Campinas: Papirus, 2004.

PARMAR, B. L. et al. Stakeholder theory: the state of art. The Academy of Management Annals. [S.1.], v. 4, n. 1, p. 403-445, 2010.

PINTO, A. L.; RIBEIRO, M. de S. Balanço social: avaliação de informações fornecidas por empresas industriais situadas no Estado de Santa Catarina. Revista Contabilidade \& Finanças - USP, São Paulo, n. 36, p. 21-34, 2004.

REIS, C. N.; MEDEIROS, L. E. Responsabilidade social das empresas e balanço social: meios propulsores do desenvolvimento econômico e social. São Paulo: atlas, 2007.

RIBEIRO, M. de F.; GESTEIRO, N. P. A busca da cidadania fiscal no desenvolvimento econômico: função social do tributo. Revista Direito Empresarial, Curitiba, v. 5, p. 195-210, 2006.

SANTOS, A. Demonstração do valor adicionado: como elaborar e analisar a DVA. 2. ed. São Paulo: Atlas, 2007. 
SANTOS, A. dos; HASHIMOTO, H. Demonstração do valor adicionado: algumas considerações sobre carga tributária. Revista de Administração da USP - RAUSP, São Paulo, v. 38, n. 2, p. 153-164, 2003.

SARLO NETO, A. et a.1. O diferencial no impacto dos resultados contábeis nas ações ordinárias e preferenciais no mercado brasileiro. Revista Contabilidade \& Finanças, São Paulo, v. 16, n. 37, p. 46-58, 2005.

SER EDUCACIONAL. Informações financeiras. Resultados. Recife, 2016. Disponível em: $<$ http://ri.sereducacional.com/sereducacional/web/conteudo_pt.asp?idioma $=0 \&$ conta $=28 \&$ tip $\mathrm{o}=47935>$. Acesso em: 19 jun. 2016.

SILVA JUNIOR, A. da; SILVA, P. de O. M. da. A desregulamentação e a abertura da educação superior à concorrência internacional: ameaça ou oportunidade? Revista Gestão Universitária na América Latina - GUAL, Florianópolis, v. 6, n. 4, Edição Especial, p. 190-215, 2013.

SILVA JUNIOR, A. da; POLIZEL, C. E. de G.; SILVA, P. de O. M. da. Os fatores críticos de sucesso para a gestão do conhecimento em uma Instituição de Educação Superior privada. Revista Brasileira de Gestão de Negócios, São Paulo, v. 14, n. 42, p. 102-122, 2012.

SILVA JUNIOR, A. da; MUNIZ, R. M. A regulamentação do ensino superior e os impactos na gestão universitária. In: COLÓQUIO INTERNACIONAL SOBRE GESTÃO UNIVERSITẢRIA NAS AMÉRICAS, 4., 2004, Florianópolis. Anais..., Florianópolis: INPEAU, 2004.

SURROCA, J.; TRIBÓ, J. A. Managerial entrenchment and corporate social performance. Journal of Business Finance \& Accounting, [S.1.], v. 35, n. 5-6, p. 748-789, 2008.

TRIPODI, T. et al. Análise de pesquisa social: diretrizes para o uso da pesquisa em serviço social e em ciências sociais. 2. ed. Rio de Janeiro: Francisco Alves, 1981.

XAVIER, W.; MARANHÃO, C. Responsabilidade social: a privatização do público. Organizações \& Sociedade, Salvador, v. 17, n. 53, p. 297-309, abr./jun. 2010. 